\title{
EXPERIMENTAL INVESTIGATION FOR TIME-DEPENDENT VARIATION OF DROPS
}

\author{
Xu Hongqing, Shao Jun and Sun Jifeng \\ SMC Tsinghua University Pneumatic Technology Center \\ Tsinghua University \\ Beijing, China, 100084
}

\begin{abstract}
With the development of science and the improvement of technology, the industrial requirement for automation is more and more eager. The application of hydraulics and pneumatics is one of the most important parts of automation. Because of the airtightness of the pneumatic executors, using lubricator is the only way to lubricate them. Under the stable air flow condition, it has been found that quantity of oil delivered by the lubricator decreases. This leads to the damage of the executors. The phenomenon of reduction of fluid discharge often occurs in engineering when fluid flows through a narrow slit as time goes on. The mechanism and law of this phenomenon must be studied so as to solve this problem. In this paper, an experimental device on needle valve is designed, and a data-acquisition software is developed. A great many experiments have been done .It has been discovered that two things account for the occurrence: adsorption and deposit of dirt. Some preliminary schemes to solve this problem are put forward in addition.
\end{abstract}

\section{KEY WORDS}

lubricator, needle valve

\footnotetext{
NOMENCLATURE

b - width of plate $(\mathrm{m})$;

$\mathrm{d}$ - inner diameter of the annulus $(\mathrm{m})$;

$\mathrm{h}$ - width of gap $(\mathrm{m})$ :

1 - length of plate $(\mathrm{m})$;
}

$$
\begin{aligned}
& q_{m}-\text { mass flowrate }(\mathrm{kg} / \mathrm{s}) \\
& q_{v}-\text { volume flowrate }\left(\mathrm{m}^{3} / \mathrm{s}\right) \\
& \operatorname{Re}-\text { Revnolds number } \\
& \mu-\text { dynamic viscosity }(\mathrm{Pa} . \mathrm{s}) \\
& \nu-\text { kinematic viscosity }\left(\mathrm{m}^{2} / \mathrm{s}\right) ;
\end{aligned}
$$


$\rho$ - density of fluid ( $\left.\mathrm{kg} / \mathrm{m}^{3}\right)$;

$\Delta p$ - the pressure drop between ends of gap $(\mathrm{Pa})$

\section{INTRODUCTION}

Pneumatics or pneumatic technology is the abbreviation for pneumatics power transmission and controls. It drives and controls various mechanical equipment to realize the mechanization and automation of production process by making use of compressed air as power source.

Lubricator is very important in pneumatic system. Various valves, cylinders and compressed air motors must be lubricated. It will result in the rise of friction force, the damage of sealing rings and the failure of seal without lubricating oil. But pneumatic components are all made up of airtight chamber so that lubricating oil can not be filled by common means.Lubricating oil must be mixed with the airflow and be taken to the lubricating place by some means or others. Lubricator is a kind of special oil feed device. It makes lubricating oil atomize into oil mist which is taken by the airflow to the component where oil adheres on them as the airflow dashes against their wall.

Different oil discharge of lubricator is demanded under different situation. The oil discharge of lubricator is controlled by a needle valve. Especially the drops of oil should be controlled exactly for the lubrication of high-speed bearings. Less drops of oil will cause the damage of bearings.

\section{FLUID CHARACTERIZATION ANALYSIS}

A kind of micro mist lubricator is used for the lubrication of high-speed bearings (see Fig. 1).

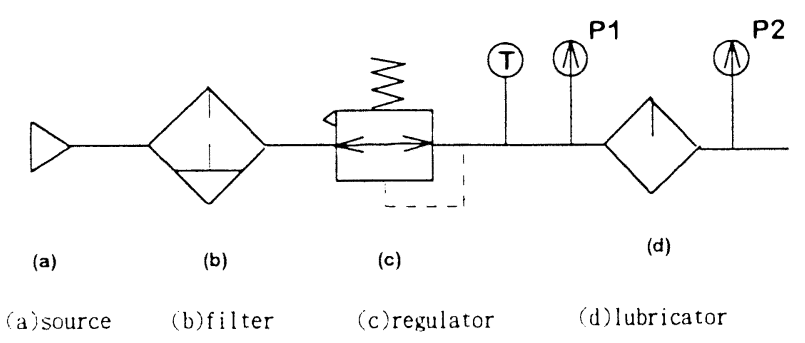

Figure 1. Lubrication for high-speed bearings
Turbine oil ISO VG32 is used in it. A large number of minute oil particles are contained in compressed air out of the lubricator. This kind of compressed air is provided for high-speed bearings. Under the conditions of steady air flow discharge and stable working pressure, it has been found that the quantity of oil delivered by lubricator decreases as time goes on. This phenomenon is also called silting phenomenon and apparently rather harmful to the bearings. But this phenomenon hardly occurs in other lubricators which lubricate the pneumatic executors such as cylinder because of the frequently change of airflow discharge and pressure fluctuation of needle valve. Thus we think the shielding phenomenon occurs in the needle valve of lubricator. The construction of needle valve of a lubricator is shown in Fig. 2. It is the very narrow gap, only $0 \sim 0.2 \mathrm{~mm}$ between needle valve spool and wall of hole, that the discharge can be adjusted in lubricator.

This phenomenon also occurs in carbonization industry.It has been analyzed theoretically by relevant references. There are several possible reasons:

\section{Impurity substance}

Impurity substance (dirt) exerts a tremendous influence usually called silting because of the narrow gap and makes it difficult to require accurate regulation of very small flows. Lubricating oil is liable to adhere on the impurity grains and block the hole. On the other hand silting is difficult to be eliminated because the dirt grains are so small that they are invisible to the naked eyes.

\section{Adsorption Membrane}

When turbine oil passes through the gap of needle valve, the interaction between oil molecules and the gap of valve, such as hydrogen bond and electrostatic effect, leads to the adherence of oil molecules on the surface of solid to form adsorption membrane. It would result in the reduction of flow discharge if the gap is rather narrow $(<0.02 \mathrm{~mm})$. There are two kinds of adsorption membrane:

\section{Physical adsorption membrane}

Physical adsorption membrane is single-layer molecule adsorption membrane formed on the metal surface with the aid of Van deer Waals attraction of lubricating oil molecules. This principle is widely applied in membrane industry. Sometimes multilayer 
molecules membrane can also form on the surface of solid in solution.

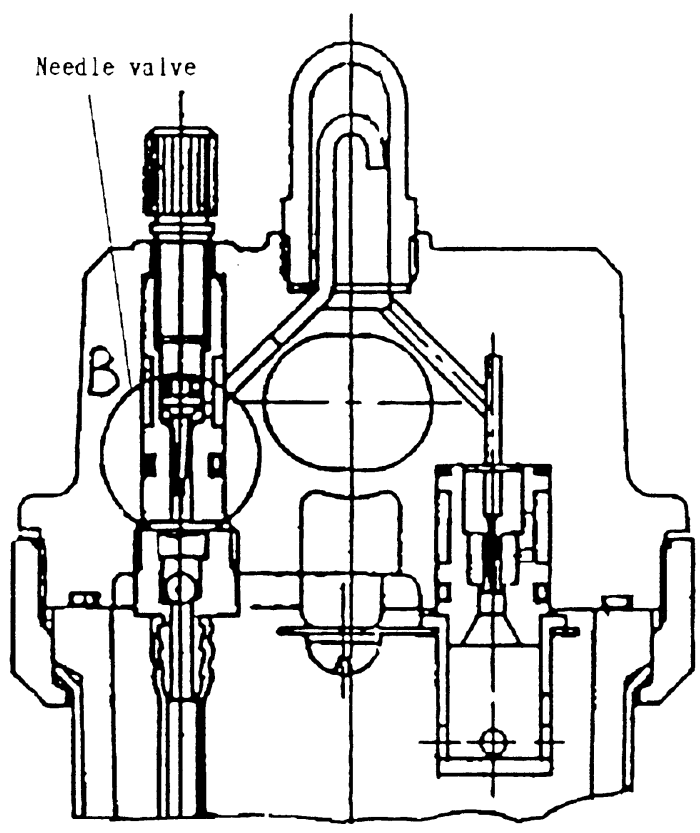

Figure 2. Construction of lubricator

\section{Chemical adsorption membrane}

The formation of chemical adsorption membrane is due to the chemical reaction between the metal surface and the oil molecules or polar molecules which have reactive bond with strong chemical binding force. Sometimes chemical adsorption membrane is about $3 \sim 5 \mu \mathrm{m}$ in thickness.

The main properties of turbine oil used in lubricators are as follows:

\section{Density}

The density of turbine oil $\rho=850-900 \mathrm{~kg} / \mathrm{m}^{3}$. The oil volume varies along with the variation of the temperature and pressure. Thus the density of oil is a function of temperature and pressure. The compressibility is neglected under normal conditions, and the density of oil is usually considered to be a constant.

\section{Viscosity}

The viscosity of mechanical oil is commonly represented by the kinematics viscosity value at $4{ }^{\circ} \mathrm{C}$ (GB 11120). The primary factors that have influence on viscosity are temperature and pressure. Oil is considered to be of high quantity with less variation along with temperature. The viscosity can be obtained by looking up relevant curves.

\section{Additives}

Lubricating oil contains various additives which are not oil but materials that dissolve in oil. Their specific gravity is similar to that of oil. They exert a tremendous influence upon the properties of oil. They must be increased or decreased according to the situation of application of oil.

\section{THEORETICAL ANALYSIS OF FLOW}

It is necessary to analyze the flow in the needle valve theoretically. The $\operatorname{Re}$ is about $1200<2200$. So we consider simply the laminar flow between fixed parallel plates.

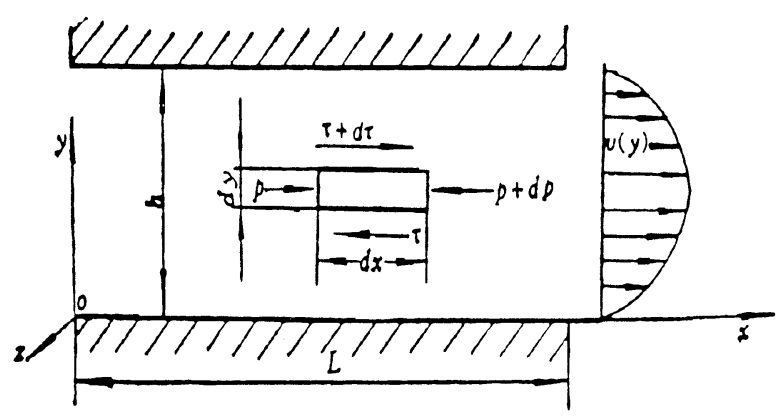

Figure 3. Flow between fixed parallel plates

We let 1 represent the length of plate, $b$ represent the width and $h$ represent the gap width, We suppose that $\mathrm{h}<<\mathrm{l}, \mathrm{h}<<\mathrm{b}$, body forces can be neglected and the viscosity $\mu$ is constant (see Fig. 3). It can be derived that the volume flowrate

$q_{v}=\frac{b h^{3}}{12 \mu} \frac{\Delta p}{l}=\frac{b h^{3}}{12 \rho v} \frac{\Delta p}{l}\left(m^{3} / s\right)$

If the width of plate b is replaced by $\pi d$, it is easy to change the formula of volume flowrate between plates into that through an axial annulus. It follows that

$q_{v}=\frac{0.154 d h^{3}}{\rho v l} \Delta p(L / \mathrm{min})$ 
According to above formula, it is discovered that volume flowrate is proportional to the pressure gradient, inversely proportional to the viscosity, and strongly dependent $\left(\sim h^{3}\right)$ on the gap width. If the gap width $h$ decreases slightly, the volume flowrate will decreases remarkably.

\section{EXPERIMENTAL INVESTIGATION}

An experimental device on needle valve has been designed and a data-acquisition software has been developed in order to research the shielding phenomenon. Experimental system is shown in Fig. 4.

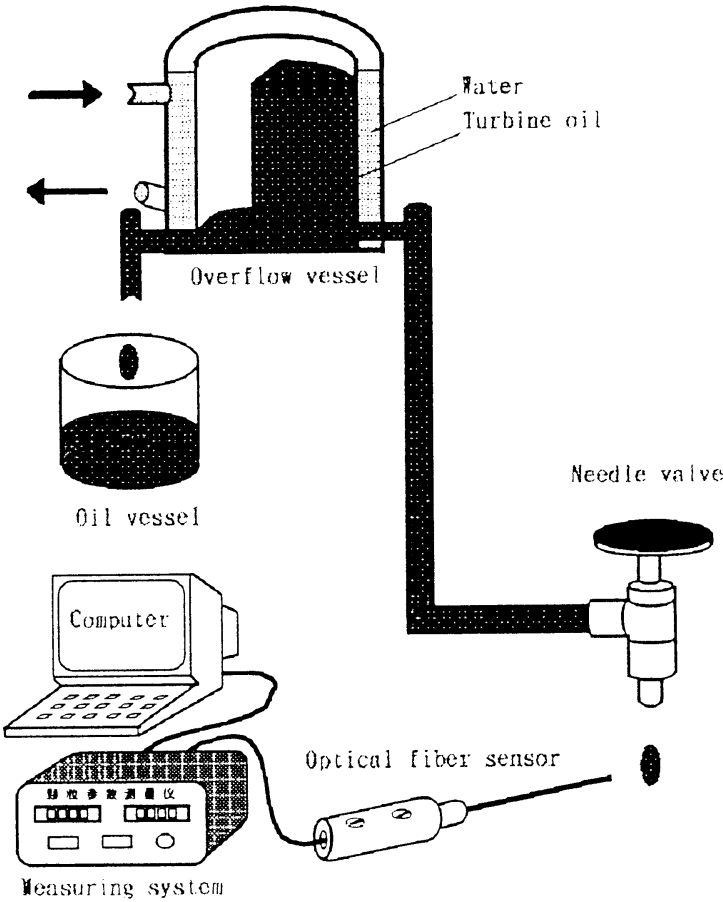

Figure 4. Experimental system

Automatically measuring system is made up of optical fiber sensor and particle parameter measuring apparatus. The value of flowrate can be recorded and displayed on the apparatus. Simultaneously the instantaneous velocity of the oil drop can be calculated and displayed by signal processing. The apparatus is also connected with computer. After hardware interruption of computer is triggered by the signal from the apparatus, the special interrupt service routine is executed to accomplish the functions of record, calculation and plot.

\section{Results and discussion}

A great many experiments have been done. Three valves for experiment are made of stainless steel: A, $\mathrm{B}$ and $\mathrm{C}$. Valve $\mathrm{A}$ is similar to that of lubricator. Valve $B$ and $C$ are different from $A$ slightly. Five grooves with $1 \mathrm{~mm}$ wide and deep are carved in B. A thin layer of PTFE resin is processed inside valve $C$.

Fig.5 Fig.8(valve A)show the silting phenomenon similar to that of lubricator. Comparing these experiments, it can be seen that the drops curve is coincident with the temperature or pressure curve. But there still exists the tendency for drops to go down. Thus we can draw a primary conclusion that the variation of temperature and pressure does not change the reduction tendency of drops.

Fig.9 Fig.18 show the experimental results of valve $\mathrm{B}$ and $\mathrm{C}$. The particle size added in colloid solution is $0.2 \mu \mathrm{m}$ or $2 \mu \mathrm{m}$. The kinematic viscosity of glycerine solution is $40 \mathrm{cSt}$ or $25 \mathrm{cSt}$.

\begin{tabular}{|l|l|l|l|l|}
\hline Fig. & \multicolumn{1}{|c|}{ medium/valve } & $\begin{array}{l}\text { begin } \\
\mathrm{d} / \mathrm{min} .\end{array}$ & $\begin{array}{l}\text { end } \\
\mathrm{d} / \mathrm{min}\end{array}$ & $\begin{array}{l}\text { reduction } \\
(\%)\end{array}$ \\
\hline 9 & distilled water $/ \mathrm{B}$ & 61 & 57 & 6.5 \\
\hline 10 & distilled water $/ \mathrm{C}$ & 60 & 56 & 6.6 \\
\hline 11 & $0.2 \mu \mathrm{m}$ particles+colloid/C & 59 & 51 & 14 \\
\hline 12 & $0.2 \mu \mathrm{m}$ particles+colloid/B & 60 & 52 & 13 \\
\hline 13 & $2 \mu \mathrm{m}$ particles+colloid/C & 60 & 12 & 80 \\
\hline 14 & $2 \mu \mathrm{m}$ particles+colloid/B & 60 & 3 & 95 \\
\hline 15 & $40 \mathrm{cStglycerine}$ solution/B & 62 & 61 & 1.6 \\
\hline 16 & $40 \mathrm{cStglycerine}$ solution/C & 62 & 60 & 3.2 \\
\hline 17 & $25 \mathrm{cStglycerine}$ solution/B & 61 & 60 & 1.6 \\
\hline 18 & $25 \mathrm{cStglycerine}$ solution/C & 61 & 60 & 1.6 \\
\hline
\end{tabular}

It can be seen from the table that two things account for the occurrence: adsorption and dirt.Deposit of dirt is the main cause(Fig.11 14). But adsorption membrane exerts a remarkably influence when valve opening is small(Fig.9 10). Thus the problem can be solved with clean oil and as large valve opening as possible.

\section{ACKNOWLEDGMENTS}

This work was supported by SMC Corporation. 


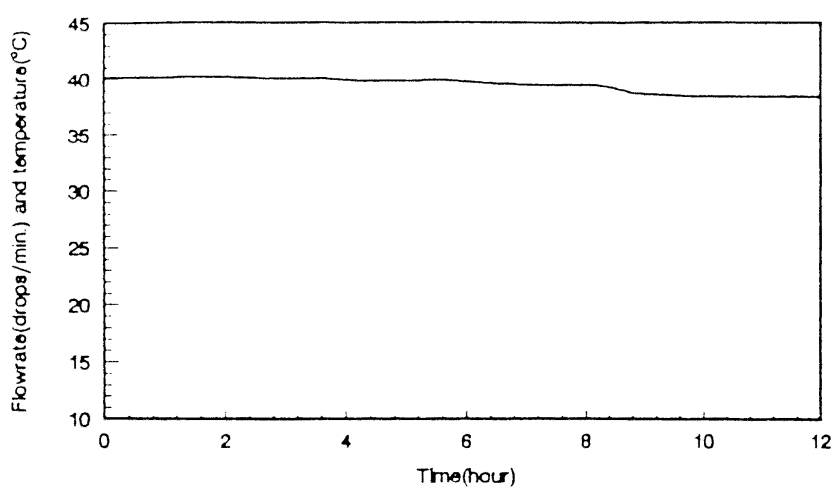

Figure 5 Result of distilled water (valve A)

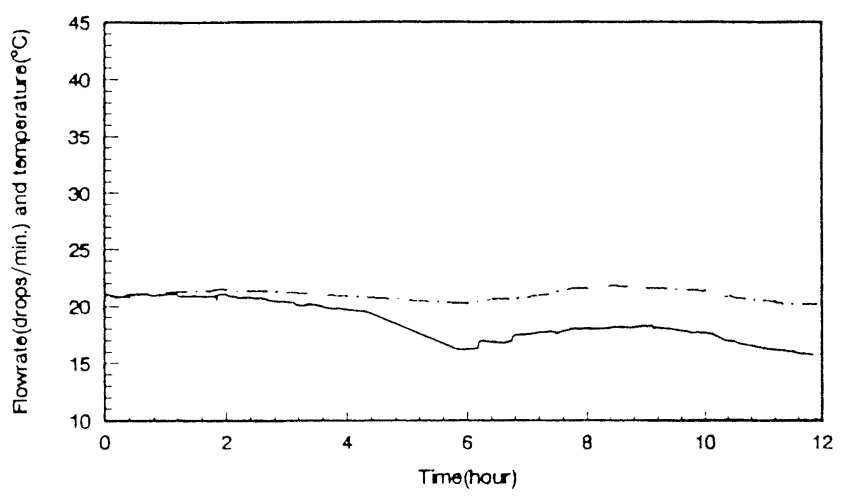

Figure 7 Result of turbine oil (valve A)

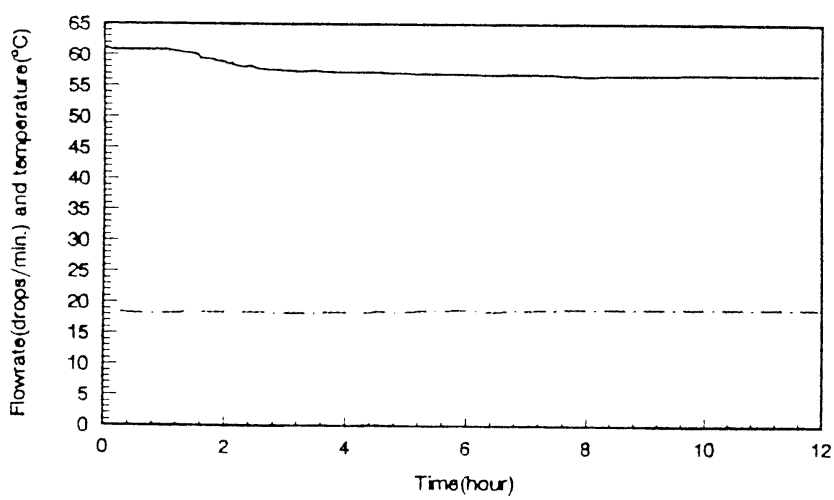

Figure 9 Result of distilled water (valve B)

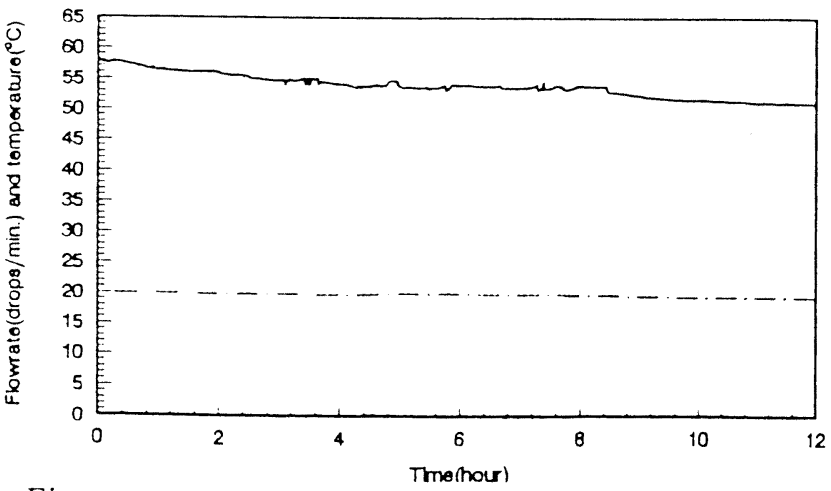

Figure 11 Result of $0.2 \mu$ mparticles+colloid(valve C)

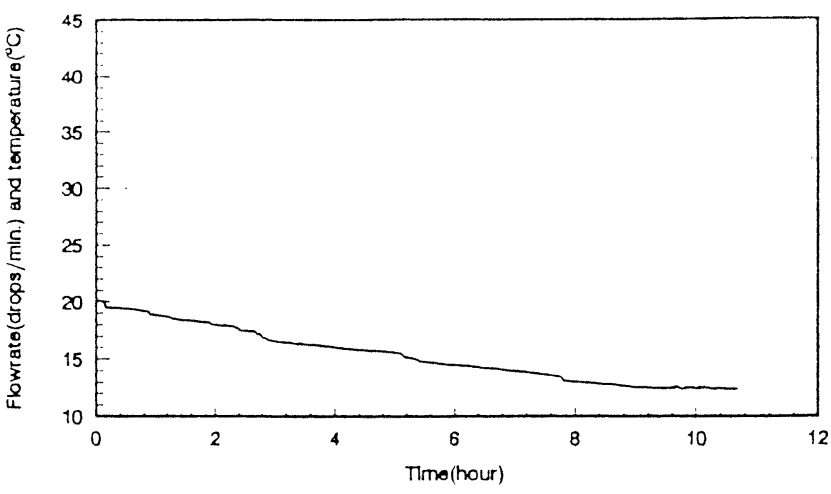

Figure 6 Result of turbine oil (valve A)

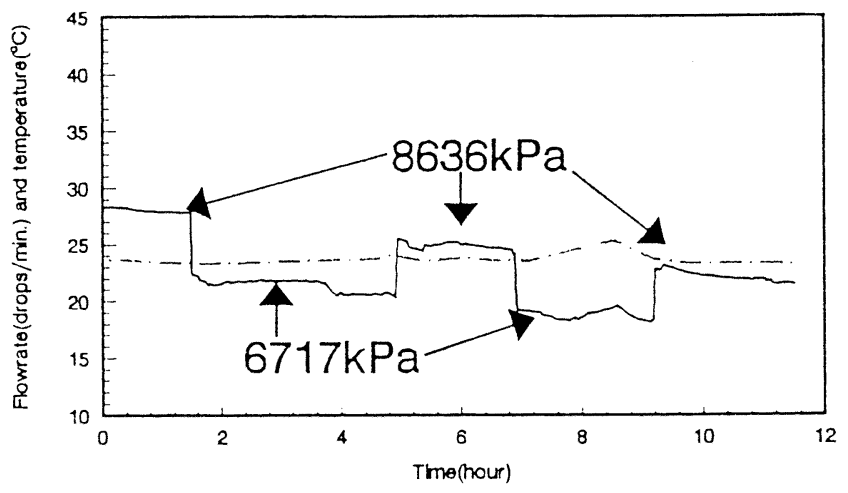

Figure 8 Result of turbine oil (valve A)

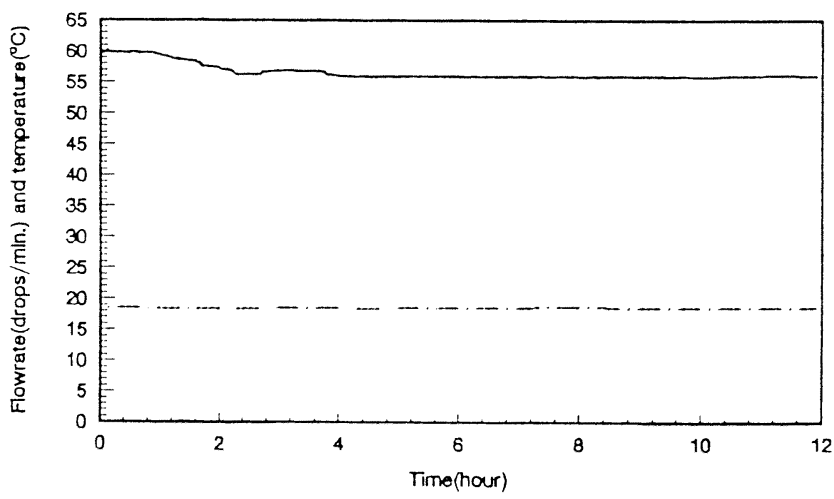

Figure 10 Result of distilled water (valve C)

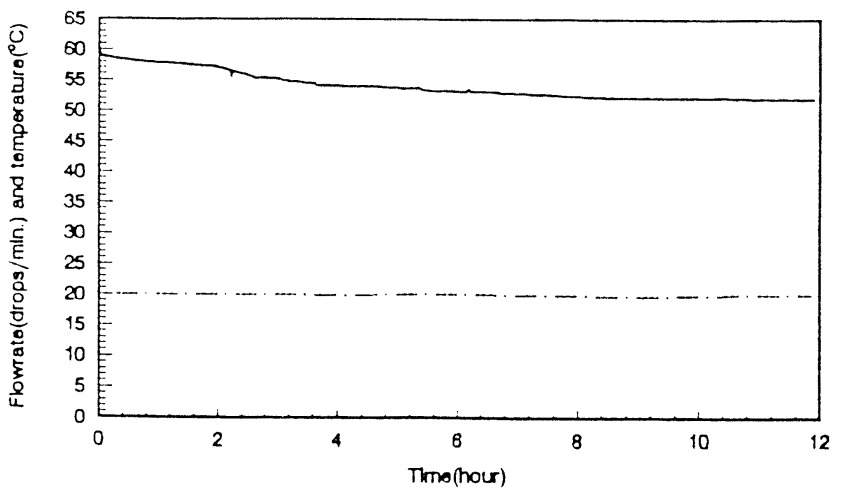

Figure 12 Result of $0.2 \mu$ mparticlestcolloid(valve B) 


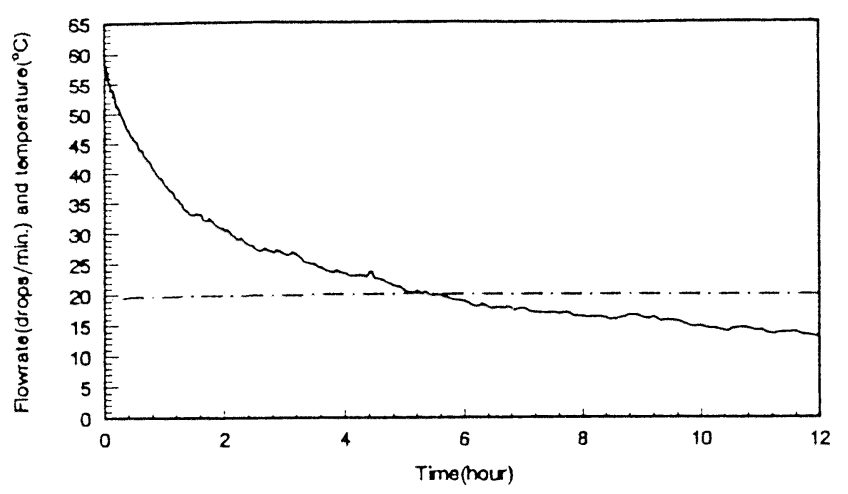

Figure 13 Result of $2 \mu$ mparticles+colloid(valve C)

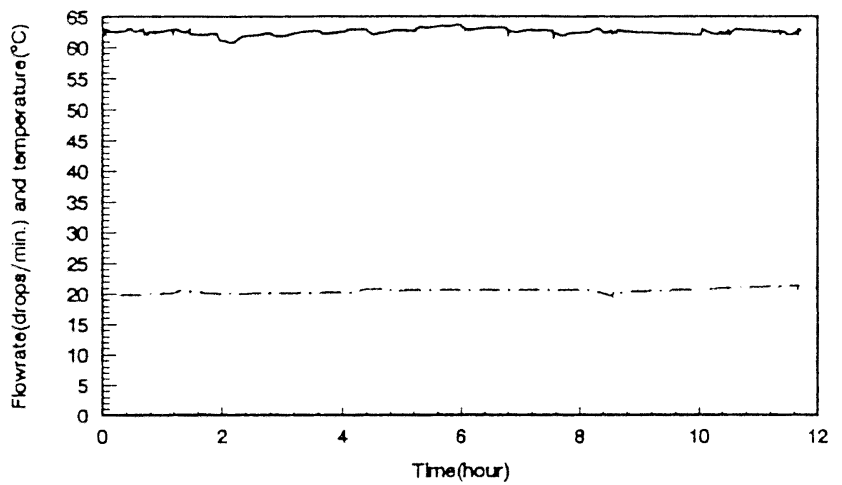

Figure 15 Result of $40 \mathrm{cSt}$ glycerine solution(valve B)

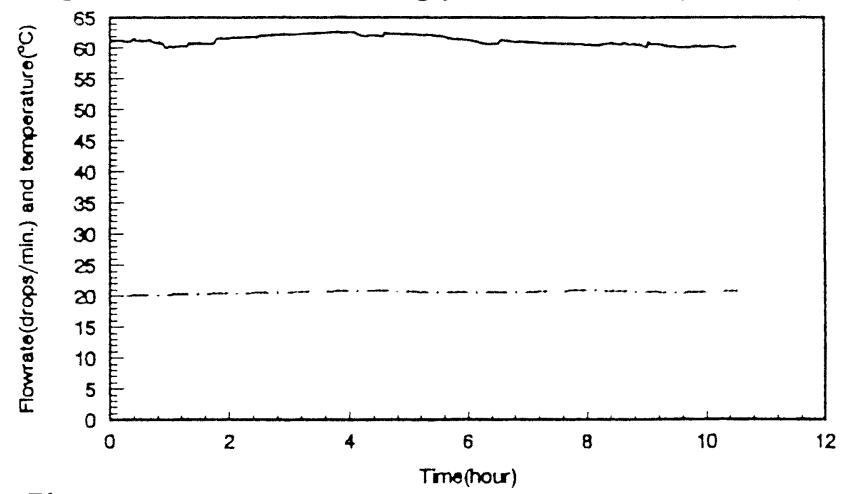

Figure 17 Result of $25 \mathrm{cSt}$ glycerine solution(valve B)

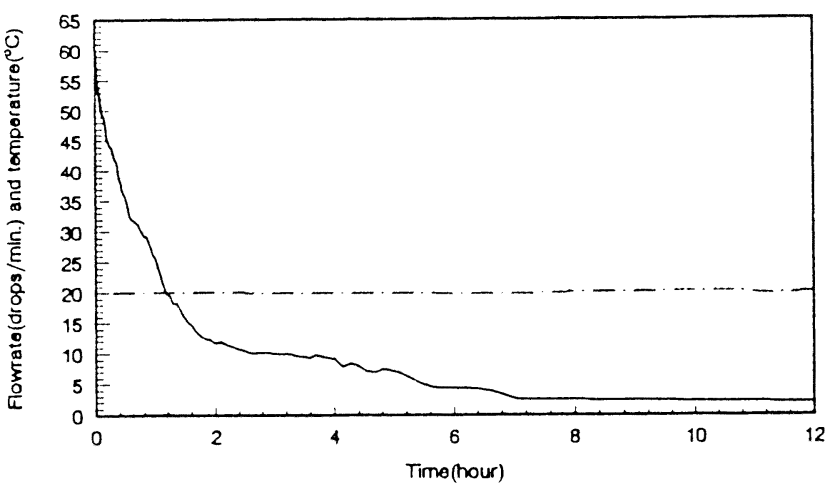

Figure 14 Result of $2 \mu$ mparticles+colloid(valve B)

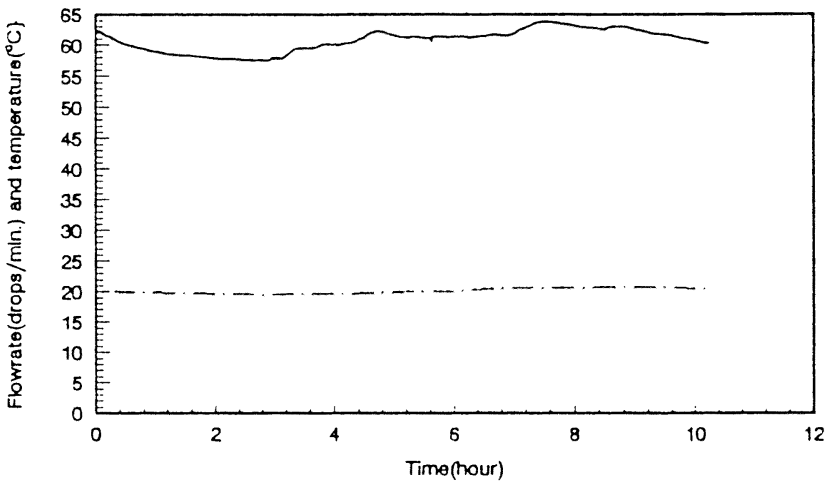

Figure 16 Result of $40 \mathrm{cSt}$ glycerine solution(valve C)

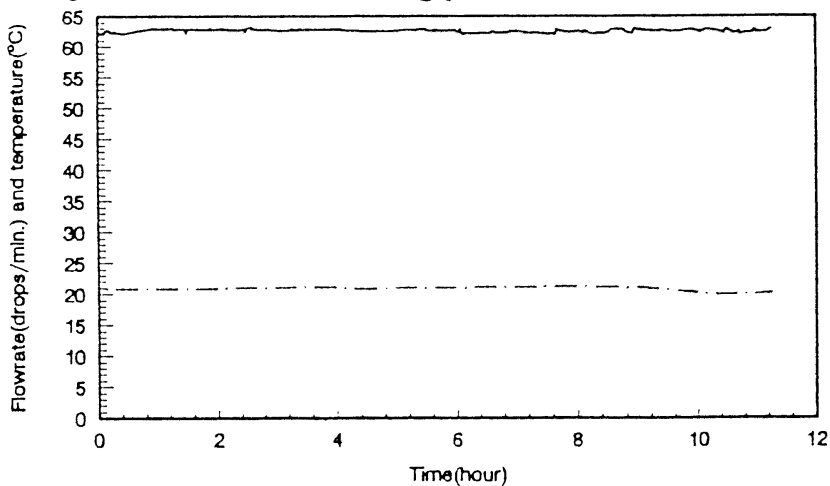

Figure 18 Result of $25 \mathrm{cSt}$ glycerine solution(valve C)

\section{REFERENCES}

1.Blackburn, J. F.,Reethof, G. and Sherer, J. L., Fluid Power Control, The technology Press of M. I. T. and John Wiley \& Sons, Inc., P294-296

2.Ou Feng and Li Xiao, Lubricating Technology of Applied Fraction Mechanical, China Standard Press, 1991 3.Yan Dafang, Design and Administration of Oil Delivery Pipe, Oil Industry Press, 1980

4.Lu Jiahe, Surface Analysis Technology, Electronics Industry Press, 1988

5.Qu Xixin, Membrane Technology, Shanghai Science and Technology Press, 1986

6. Wang Tingshu and Yu Congxi, Hydraulic and Pneumatic Technology, National Defense Industry Press, 1988

7.OR. Runge, Friction Bearings, Engineering Industry Press, 1986

8.Xu Shangxian, Design of Hydrostatic and Hydrodynamic Bearings, Southeast University Press, 1989

9.Zhang. Ke-jian, Study on the Stabilization of the Dripping Qantity of a Dripfeed Device in Carburizing Furnace,

Heat Treatment for Metal, 1987,5 